\title{
Association Between Dose Reduction Of Renin- Angiotensin-Aldosterone System Inhibitors Before Coronary Artery Angiography And Acute Kidney Injury: A Propensity Matched Study
}

Hiroyuki Hashimoto

Kyoto University

Masato Takeuchi ( $\nabla$ takeuchi.masato.3c@kyoto-u.ac.jp)

Kyoto University

Koji Kawakami

Kyoto University

\section{Research Article}

Keywords: AKI, contrast-induced nephropathy, contrast media, coronary artery angiography, RAAS inhibitor

Posted Date: February 7th, 2022

DOI: https://doi.org/10.21203/rs.3.rs-1298117/v1

License: (a) (1) This work is licensed under a Creative Commons Attribution 4.0 International License.

Read Full License 


\section{Abstract}

Background: Acute kidney injury (AKI), which is commonly observed in hospitalized patients, increases mortality. Although renin-angiotensin-aldosterone system inhibitors (RAASis) and coronary artery angiography (CAG) are reported to be risk factors for AKI, whether dose reduction of RAASis can prevent AKI after CAG remains unknown. The objective of this study was to investigate the association between dose reduction of RAASis and AKI.

Methods: In this retrospective propensity score (PS)-matched cohort of patients with an estimated glomerular filtration rate (eGFR) of $15-60 \mathrm{ml} / \mathrm{min} / 1.73 \mathrm{~m}^{2}$ who were prescribed RAASis, we examined the impact of dose reduction of RAASis on the development of AKI after CAG with the RWD database, which includes 20 million patients from 190 hospitals in Japan. The exposure of interest was the presence of a dose reduction in RAASis within the 3 days before CAG was performed. The propensity score was derived from 19 baseline characteristics using a logistic regression model.

Results: We identified 3,289 patients who were prescribed RAASis at least one month before admission and underwent CAG. Six hundred seventy-four patients had a dose reduction 3 days prior to undergoing CAG, and 2,640 patients did not. AKI was observed in 42 (4.7\%) patients in the reduction group and 121 (5.1\%) patients in the control group. There was no significant difference in the primary outcome between the two groups in the PS-matched cohort (OR: 1.00, 95\% Cl: 0.69-1.47).

Conclusions: A reduction in the dose of RAASis did not prevent the development of AKI among patients undergoing CAG.

\section{Introduction}

Acute kidney injury (AKI), a condition that is observed in 10.5 to $22.0 \%$ of inpatients, increases mortality and prolongs the hospital stay [1-3]. Renin-angiotensin-aldosterone system inhibitors (RAASis) and coronary artery angiography (CAG) are reported to be risk factors for AKI [4-6]. Although some doctors empirically reduce the dose of RAASis before performing CAG, whether dose reduction of RAASis can prevent AKI remains unclear. Three randomized controlled trials (RCTs) were conducted to confirm the efficacy of the dose reduction of RAASis on renal function in patients undergoing CAG; however, there were no differences in the development of AKI between the reduction group and the control group in any of the studies [7-10]. These results may be due to the following two issues. First, the sample size was small in all studies. Second, the RAASi dose was reduced within 24 hours before CAG. The timing of reduction was too late in all studies considering the half-life of RAASis, which is reported to be up to 24 hours [11]. For these reasons, a study with a longer reduction period and a larger sample size is needed to assess the efficacy of the dose reduction in RAASis for preventing AKI. The objective of this study was to investigate the association between dose reduction of RAASis and AKI among patients undergoing CAG using a Japanese healthcare record database. 


\section{Methods}

\section{Study design and setting}

The RWD database, which is administered by the Health, Clinic and Education Information Evaluation Institute (HCEl, Kyoto, Japan), was used for this retrospective cohort study [12,13]. The HCEl is a not-forprofit research service foundation in Japan. Real World Data Co., Ltd. (Kyoto, Japan) supports the HCEI for data collection and standardization support. The RWD database includes the data of 20 million patients from 160 hospitals in Japan. This information consists of demographic data, prescriptions, laboratory results, diagnoses with International Statistical Classification of Diseases and Related Health Problems, 10th Revision Codes (ICD-10 codes) and inpatient and outpatient procedures. These data are handled by allocating a unique identifier to each individual. We did not link these data with any other databases.

\section{Data Collection And Definitions}

We included inpatients aged 18 or older who were prescribed RAASis for at least one month prior to admission and were undergoing CAG during hospitalization between April 2005 and March 2019. Only first admissions with CAG were included in our study. To restrict the focus to patients at risk of AKI, only patients with an estimated glomerular filtration rate (eGFR) of $15-60 \mathrm{ml} / \mathrm{min} / 1.73 \mathrm{~m}^{2}$ were included. Patients undergoing dialysis within 3 days after admission were excluded. Patients with missing values for the primary diagnosis were also excluded because the primary diagnosis was treated as one of the explanatory variables in a previous study and may influence the incidence of AKI [14]. The exposure of interest was the presence of a dose reduction in RAASis during the 3 days before CAG was performed. The definition of dose reduction in RAASis was the change in the ratio of the prescribed dose to the defined daily dose (dose/DDD), which is defined by the World Health Organization [15, 16]. We calculated the dose/DDD of RAASis for all days during hospitalization. If the dose/DDD was reduced, the patient was considered to have received a dose reduction of the RAASi and was included in the reduction group. For example, even if there was a change from angiotensin receptor blocker (ARB) to angiotensinconverting enzyme inhibitor (ACEi), we considered that as no reduction unless there was a change in the dose/DDD. We included both discontinuation and dose reduction in the exposure group to avoid misclassification of discontinuation of only one medication for patients prescribed two or more RAASis. The difference in the impact on the development of AKI between discontinuation and reduction (excluding discontinuation) was assessed in the subgroup analysis.

\section{Propensity Score Matching}

We calculated the propensity score (PS) of each patients to balance the baseline characteristics of each group [17-19]. The PS was estimated using a logistic regression model. The explanatory variables for the model are age, sex, Charlson Comorbidity Index (CCI) score, intensive care unit admission, baseline serum 
creatinine defined as the last measured serum creatinine before CAG, primary diagnosis on admission [14], infection [20], acute heart failure, hyponatremia, transfusion, hydration with extracellular fluid, $\mathrm{N}$ acetyl cysteine, platinum-based chemotherapy, and the use of diuretics, amphotericin B, aminoglycosides, glycopeptides, and nonsteroidal anti-inflammatory drugs. The definitions of these explanatory variables are described in Supplementary data, Table S1. To ensure balancing between the two groups, calipers were defined as 0.1 , and $1: 2$ nearest neighbor matching was applied to maintain statistical power. Standardized differences were used to assess comparability between the two matched cohorts.

\section{Sample Size Calculation}

We also estimated the needed sample size to detect the difference in the development of AKI between the two groups because the present study was planned based on the hypothesis that previous studies did not include a sufficient number of patients. The incidence of AKI was set at $10 \%$ in the reduction group and $15 \%$ in the control group [1-3]. The effect size was based on a systematic review of 3 RCTs [9]. The required sample size was calculated to be 525 in the reduction group and 1,050 in the control group, assuming an alpha error of 0.05 , a power of 0.8 , and an enrollment ratio of 1:2.

\section{Outcome Measures}

The primary outcome was AKI defined as an absolute increase in serum creatinine of $\geq 0.3 \mathrm{mg} / \mathrm{dl}$ from baseline within 48 hours or a relative increase in serum creatinine of $\geq 50 \%$ within 7 days [21]. We adopted the definition of AKI as renal injury after contrast use. This is because the Kidney Disease: Improving Global Outcome (KDIGO) guidelines indicated that contrast-induced nephropathy should be evaluated under the same criteria as AKI [21]. The secondary outcomes were the need for dialysis and inhospital mortality.

\section{Statistical analysis}

Continuous variables were reported as the mean and standard deviation, and categorical variables were reported as numbers and percentages. First, we described the characteristics of the patients in each group. Binary logistic regression was used to assess significant univariate associations between the reduction group and the control group with the outcomes for the PS-matched cohort. The results are presented as odds ratios (ORs) and $95 \%$ confidence intervals (Cls). We defined the main result as the OR in the PS-matched cohort.

Sensitivity analysis was performed by changing the period of time of dose reduction from 1 to 14 days to detect the appropriate timing of dose reduction of RAASis. We also performed subgroup analysis investigating the interaction with age ( $\leq 65$ and $>65$ ), type of RAASi (ARB, ACEi, aldosterone blocker and direct renin inhibitor (DRI)), past history of diabetes, baseline eGFR $(\leq 30,30-45$ and $>45 \mathrm{ml} / \mathrm{min} / 1.73$ 
$\mathrm{m}^{2}$ ) and dose reduction or discontinuation. P-values with a two-sided test were reported, and $\mathrm{P}<0.05$ was considered to indicate statistical significance. We used $\mathrm{R}$ ver. 4.1.2 to perform all statistical analyses.

\section{Results}

We identified 11,172 patients who were prescribed RAASis at least one month before admission and who underwent CAG during hospitalization from April 2005 to March 2019. Finally, 7803 patients were excluded for reasons such as age, baseline eGFR, undergoing dialysis within three days after admission and no primary diagnosis, and 3,289 patients were included in this retrospective cohort study (Fig. 1). Eight hundred ninety-six patients were included in the reduction group, and 2,393 were included in the control group in the entire cohort. A total of 2,640 patients were matched using PS. After PS matching, 896 patients were included in the reduction group, and 1,744 were included in the control group. The baseline characteristics of each group in the entire cohort and PS-matched cohort are described in Table 1. The standardized differences for all variables were balanced after PS matching [17, 22]. AKI was observed in $42(4.7 \%)$ patients in the reduction group and in $121(5.1 \%)$ patients in the control group in the entire cohort. The risk of developing AKI was not different between the reduction group and the control group in the entire cohort (OR: 0.92, 95\% Cl: 0.64-1.32). In terms of the need for dialysis and inhospital death, there were no significant differences between the two groups in the entire cohort (Table 2). As the main result, the risk of developing AKI was similar between the two groups in the PS-matched cohort (OR: $1.00,95 \% \mathrm{Cl}$ : 0.69-1.47). Regarding the secondary outcomes, the risk of need for dialysis and in-hospital death were not significantly different between the two groups in the PS-matched cohort (Table 2). 
Table 1

Baseline characteristics of each group in the entire cohort and PS-matched cohort

\begin{tabular}{|c|c|c|c|c|c|c|}
\hline & \multicolumn{3}{|l|}{ Entire cohort } & \multicolumn{3}{|c|}{ PS-matched cohort } \\
\hline & Cases in & Cases in & SDif & Cases in & Cases in & SDif \\
\hline & $\begin{array}{l}\text { Reduction } \\
\text { Group }\end{array}$ & $\begin{array}{l}\text { Control } \\
\text { Group }\end{array}$ & & $\begin{array}{l}\text { Reduction } \\
\text { Group }\end{array}$ & $\begin{array}{l}\text { Control } \\
\text { Group }\end{array}$ & \\
\hline & $(n=896)$ & $(n=2393)$ & & $(n=896)$ & $(n=1744)$ & \\
\hline Male (\%) & $599(66.9)$ & $\begin{array}{l}1606 \\
(67.1)\end{array}$ & 0.01 & $599(66.9)$ & $\begin{array}{l}1180 \\
(67.7)\end{array}$ & 0.02 \\
\hline Age (mean (SD)) & $74.6(9.0)$ & $74.9(8.8)$ & 0.03 & $74.6(9.0)$ & $74.6(9.0)$ & 0.00 \\
\hline $\mathrm{CCl}($ mean $(\mathrm{SD}))$ & $5.4(3.5)$ & $5.3(3.5)$ & 0.03 & $5.4(3.5)$ & $5.4(3.5)$ & 0.01 \\
\hline eGFR (mean (SD)) & $44.9(10.7)$ & $\begin{array}{l}45.1 \\
(10.6)\end{array}$ & 0.02 & $44.9(10.7)$ & $\begin{array}{l}44.9 \\
(10.5)\end{array}$ & 0.00 \\
\hline Diuretics (\%) & $494(55.1)$ & $\begin{array}{l}1128 \\
(47.1)\end{array}$ & 0.16 & $494(55.1)$ & $942(54.0)$ & 0.02 \\
\hline NSAID (\%) & $69(7.7)$ & $127(5.3)$ & 0.10 & $69(7.7)$ & $111(6.4)$ & 0.05 \\
\hline Heart failure & $24(2.7)$ & $81(3.4)$ & 0.04 & $24(2.7)$ & $45(2.6)$ & 0.01 \\
\hline Platinum (\%) & $0(0.0)$ & $1(0.0)$ & 0.03 & $0(0.0)$ & $0(0.0)$ & - \\
\hline Aminoglycoside (\%) & $0(0.0)$ & $1(0.0)$ & 0.03 & $0(0.0)$ & $0(0.0)$ & - \\
\hline Glycopeptide (\%) & $2(0.2)$ & $1(0.0)$ & 0.05 & $2(0.2)$ & $0(0.0)$ & 0.07 \\
\hline NAC (\%) & $0(0.0)$ & $0(0.0)$ & - & $0(0.0)$ & $0(0.0)$ & - \\
\hline Sodium bicarbonate (\%) & $0(0.0)$ & $17(0.7)$ & 0.12 & $0(0.0)$ & $0(0.0)$ & - \\
\hline Hydration (\%) & $366(40.8)$ & $\begin{array}{l}1193 \\
(49.9)\end{array}$ & 0.18 & $366(40.8)$ & $725(41.6)$ & 0.01 \\
\hline Infection (\%) & $4(0.4)$ & $5(0.2)$ & 0.04 & $4(0.4)$ & $5(0.3)$ & 0.03 \\
\hline Operation (\%) & $28(3.1)$ & $84(3.5)$ & 0.02 & $28(3.1)$ & $46(2.6)$ & 0.03 \\
\hline Transfusion (\%) & $49(5.5)$ & $126(5.3)$ & 0.01 & $49(5.5)$ & $85(4.9)$ & 0.03 \\
\hline ICU admission (\%) & $38(4.2)$ & $119(5.0)$ & 0.04 & $38(4.2)$ & $73(4.2)$ & 0.00 \\
\hline \multicolumn{7}{|l|}{ Admission year } \\
\hline$-2012(\%)$ & $99(11.0)$ & $259(10.8)$ & 0.01 & $99(11.0)$ & $183(10.5)$ & 0.02 \\
\hline
\end{tabular}
anti-inflammatory drug; PS, propensity score; SD, standard deviation; SDif, standardized difference. 


\begin{tabular}{|c|c|c|c|c|c|c|}
\hline \multirow[b]{2}{*}{ 2013-2016 (\%) } & \multicolumn{3}{|c|}{ Entire cohort } & \multicolumn{3}{|c|}{ PS-matched cohort } \\
\hline & $390(43.5)$ & $\begin{array}{l}1262 \\
(52.7)\end{array}$ & -0.18 & $390(43.5)$ & $805(46.2)$ & -0.05 \\
\hline 2017-2019 (\%) & $407(45.4)$ & $872(36.4)$ & 0.18 & $407(45.4)$ & $756(43.3)$ & 0.04 \\
\hline \multicolumn{7}{|l|}{ Primary diagnosis } \\
\hline Cardiovascular (\%) & $731(81.6)$ & $\begin{array}{l}1903 \\
(79.5)\end{array}$ & 0.05 & $731(81.6)$ & $\begin{array}{l}1441 \\
(82.6)\end{array}$ & -0.03 \\
\hline Other (\%) & $31(3.5)$ & $89(3.7)$ & -0.01 & $41(4.6)$ & $78(4.5)$ & 0.02 \\
\hline Metabolic (\%) & $30(3.3)$ & $103(4.3)$ & -0.05 & $31(3.5)$ & $54(3.1)$ & 0.01 \\
\hline Cerebrovascular (\%) & $16(1.8)$ & $53(2.2)$ & -0.03 & $30(3.3)$ & $54(3.1)$ & 0.01 \\
\hline Digestive (\%) & $15(1.7)$ & $39(1.6)$ & 0.01 & $16(1.8)$ & $29(1.7)$ & 0.01 \\
\hline $\begin{array}{l}\text { Septicemia/other } \\
\text { infections (\%) }\end{array}$ & $15(1.7)$ & $35(1.5)$ & 0.02 & $15(1.7)$ & $28(1.6)$ & 0.01 \\
\hline Injury/Poisoning (\%) & $10(1.1)$ & $18(0.8)$ & 0.03 & $15(1.7)$ & $28(1.6)$ & 0.00 \\
\hline Neoplasm (\%) & $3(0.3)$ & $12(0.5)$ & -0.03 & $10(1.1)$ & $17(1.0)$ & 0.00 \\
\hline Peripheral vascular (\%) & $3(0.3)$ & $7(0.3)$ & 0.00 & $3(0.3)$ & $7(0.4)$ & -0.02 \\
\hline Respiratory (airway) (\%) & $1(0.1)$ & $2(0.1)$ & 0.00 & $3(0.3)$ & $6(0.3)$ & 0.00 \\
\hline $\begin{array}{l}\text { Respiratory } \\
\text { (parenchymal) (\%) }\end{array}$ & $41(4.6)$ & $132(5.5)$ & -0.04 & $1(0.1)$ & $2(0.1)$ & 0.01 \\
\hline
\end{tabular}

Table 2

Odds ratios for AKI, in-hospital dialysis and in-hospital death in the entire cohort and in the PS-matched cohort

\begin{tabular}{|c|c|c|c|c|c|c|}
\hline & \multicolumn{3}{|l|}{ Entire cohort } & \multicolumn{3}{|c|}{ PS-matched cohort } \\
\hline & $\begin{array}{l}\text { Events in } \\
\text { Reduction group }\end{array}$ & $\begin{array}{l}\text { Events in } \\
\text { Control group }\end{array}$ & $\begin{array}{l}\text { Odds Ratio } \\
(95 \% \mathrm{Cl})\end{array}$ & $\begin{array}{l}\mathrm{P} \\
\text { Value }\end{array}$ & $\begin{array}{l}\text { Odds Ratio } \\
(95 \% \mathrm{Cl})\end{array}$ & $\begin{array}{l}\mathrm{P} \\
\text { Value }\end{array}$ \\
\hline AKI & $42(4.7)$ & $121(5.1)$ & $\begin{array}{l}0.92(0.64- \\
1.32)\end{array}$ & 0.66 & $\begin{array}{l}1.00(0.69- \\
1.47)\end{array}$ & 0.98 \\
\hline $\begin{array}{l}\text { Dialysis in } \\
\text { hospital }\end{array}$ & $16(1.8)$ & $24(1.0)$ & $\begin{array}{l}1.79(0.95- \\
3.39)\end{array}$ & 0.07 & $\begin{array}{l}1.98(0.98- \\
3.97)\end{array}$ & 0.06 \\
\hline $\begin{array}{l}\text { Death in } \\
\text { hospital }\end{array}$ & $13(1.5)$ & $31(1.3)$ & $\begin{array}{l}1.12(0.58- \\
2.15)\end{array}$ & 0.73 & $\begin{array}{l}1.28(0.63- \\
2.58)\end{array}$ & 0.49 \\
\hline
\end{tabular}




\section{Sensitivity Analysis}

As a sensitivity analysis, we performed the analyses by changing the periods of dose reduction of RAASis to $1,3,7$ and 14 days. The OR was 1.07 (95\% Cl: 0.69-1.65) for the period of 1 day and 0.99 (95\% Cl: $0.71-$ 1.39) for the period of 14 days. The results of the sensitivity analysis are shown in Table 3 . There was no significant difference between the reduction group and the control group for any length of reduction in the PS-matched cohort.

Table 3

Sensitivity analysis changing the length of the period of dose reduction in the PS-matched cohort

\begin{tabular}{|lll|}
\hline & Odds Ratio $(95 \%$ Cl) & P Value \\
\hline 1 day & $1.07(0.69-1.65)$ & 0.76 \\
\hline 3 days & $1.00(0.69-1.47)$ & 0.98 \\
\hline 7 days & $1.07(0.77-1.50)$ & 0.68 \\
\hline 14 days & $0.99(0.71-1.39)$ & 0.96 \\
\hline
\end{tabular}

\section{Subgroup Analysis}

We performed subgroup analysis for age, type of RAASi, past history of diabetes and baseline eGFR to investigate the interaction with the dose reduction of RAASis. The results of the subgroup analysis are presented in Table 4. In terms of the type of RAASi, the sample size of the DRI subgroup was not enough to calculate the odds ratio, and we could not assess the interaction with reduction. For the other 3 types of RAASis, age, past history of diabetes, baseline eGFR and degree of reduction, no significant difference was observed between the two groups among all subgroups. 
Table 4

Subgroup analysis investigating interactions with age, type of RAASi, baseline eGFR and degree of reduction.

\begin{tabular}{|c|c|c|}
\hline & Odds Ratio (95\% Cl) & P Value \\
\hline \multicolumn{3}{|l|}{ Age } \\
\hline Age $>65$ & $1.14(0.71-1.83)$ & 0.59 \\
\hline Age $\leq 65$ & $0.59(0.23-1.51)$ & 0.27 \\
\hline \multicolumn{3}{|l|}{ Type of RAASi } \\
\hline ACEi & $0.69(0.30-1.57)$ & 0.37 \\
\hline ARB & $1.31(0.80-2.16)$ & 0.29 \\
\hline Aldosterone Blocker & $1.00(0.00-\operatorname{lnf})$ & 1.00 \\
\hline DRI & Not enough cases to calculate & Not applicable \\
\hline \multicolumn{3}{|l|}{ Diabetes } \\
\hline Yes & $0.90(0.30-2.64)$ & 0.84 \\
\hline No & $1.05(0.66-1.68)$ & 0.83 \\
\hline \multicolumn{3}{|l|}{ Baseline eGFR } \\
\hline eGFR $>45$ & $0.78(0.30-2.03)$ & 0.61 \\
\hline $30<\mathrm{eGFR} \leq 45$ & $1.31(0.72-2.40)$ & 0.37 \\
\hline eGFR $\leq 30$ & $0.88(0.34-2.26)$ & 0.79 \\
\hline \multicolumn{3}{|l|}{ Degree of reduction } \\
\hline Discontinuation & $1.48(0.76-2.89)$ & 0.25 \\
\hline Reduction (excluding discontinuation) & $0.86(0.49-1.51)$ & 0.60 \\
\hline
\end{tabular}

\section{Discussion}

In the analysis of the PS-matched cohort of 2,640 patients undergoing CAG at risk of AKI, we did not find any association between the reduction in the dose of RAASis and the development of AKI. The results were not changed in the sensitivity analysis. Moreover, no interactions were observed between the dose reduction of RAASis and age, the type of RAASi and baseline eGFR in subgroup analysis. The dose reduction of RAASis was not associated with the need for dialysis or in-hospital mortality. 
Our findings were consistent with those of previous randomized controlled trials and systematic reviews [7-10]. In previous studies, there were no associations between a reduction in RAASi dose and the development of AKI or contrast-induced nephropathy (CIN). We hypothesized that these negative results were due to the small sample size and the excessively short period of RAASi dose reduction. Although the current study was designed to resolve these issues, the results were consistent with previous studies.

One possible explanation for these results may be attributed to hydration. Generally, RAASi treatment reduces the blood flow of the glomerulus by lowering blood pressure and dilating efferent arterioles [23, 24]. Contrast media also reduces the blood flow of the glomerulus through vasoconstriction [25-27]. Acute kidney injury is thought to develop due to the synergistic effect of the decrease in renal blood flow caused by contrast and by RAASi treatment. However, as shown in the present study, $49.1 \%$ of the control group received extracellular fluid infusion, which may have interfered with the mechanism of AKI development. Hydration with extracellular fluid infusion may have closed the gap between the two groups and resulted in no difference. Some studies have reported that hydration can prevent the development of AKI after contrast use [28, 29].

\section{Strengths And Limitations}

There are 3 strengths in this study. First, we applied PS matching to balance the baseline characteristics between the reduction group and the control group. In the absence of randomization, establishment of a valid comparison is increasingly found in previous studies [18, 30-32]. This method has been recommended for assessing the association between contrast and AKI [30,33]. Moreover, it allowed us to estimate the odds ratio directly. Second, the sample size was much larger than that in previous studies. Even in the systematic review [9], the cumulative sample size of the RCTs was just 522 for this clinical question, and no association was observed between dose reduction and the development of AKI. We calculated the required sample size in advance and performed the analysis with higher statistical power than that in previous studies. In addressing the sample size issues, our study is meaningful because it cannot be resolved by RCTs. Considering that there was no significant difference between the two groups even with a sufficient sample size and that the OR was 1.00 in the PS-matched cohort, the potential effect size of the dose reduction of RAASis would be trivial compared to hydration and other interventions, which were reported to have ORs of $0.29-0.31[29,34,35]$. Finally, we performed a sensitivity analysis by changing the periods of reduction in RAASi dose. The results were consistent from a period of 1 day to 14 days. Because various types of RAASis were prescribed to the subjects and the half-life varied from 2 to 24 hours [11], this sensitivity analysis was absolutely required to make our results robust.

The main limitation of retrospective cohort studies is unmeasured confounders, such as the results of echocardiography. Such confounders cannot be adjusted in our retrospective cohort and may have some impacts on our results. Second, the number of subjects prescribed DRIs and aldosterone blockers in the subgroup analysis was not enough to precisely assess the impact of dose reduction. Although the OR of aldosterone blockers could be calculated, the $95 \% \mathrm{Cl}$ was much wider than that of ARB and ACEi. The efficacy of the dose reduction of those two drugs was unknown in our study. Last, we note the lack of 
data on urine output. AKI was diagnosed based only on laboratory data and not on the reduction in urine output in the current study. Although there may be misclassification of AKI in both groups, we believe that the duration of 7 days to assess the development of $A K I$ is long enough to reflect the reduction in urine output through a change in laboratory data [36].

\section{Conclusions}

A reduction in the dose of RAASis did not prevent the development of $\mathrm{AKI}$ among patients undergoing CAG.

\section{Declarations}

\section{Ethics approval and consent to participate}

This study was approved by Kyoto University Graduate School and Faculty of Medicine, Ethics Committee. We performed this study in accordance with the ethical standards set down in the 1964 Declaration of Helsinki and its later amendments. The ethics committee determined that individual consent was not needed because the data were anonymized and the current study was retrospective.

\section{Consent for publication}

Not applicable.

\section{Availability of data and materials}

Data sharing is not permitted under HCEl policy. If readers are interested in our dataset, please contact HCEI for data availability (https://www.hcei.or.jp).

\section{Competing Interests}

Koji Kawakami has received research funds from Eisai Co., Ltd.; Kyowa Kirin Co., Ltd.; Sumitomo Dainippon Pharma Co., Ltd.; Pfizer Inc.; Stella Pharma Corporation; CMIC Co., Ltd.; Suntory Beverage \& Food Ltd.; Mitsubishi Corporation, and Real World Data Co., Ltd.; consulting fees from LEBER Inc.; JMDC Inc.; Shin Nippon Biomedical Laboratories Ltd.; Kaken Pharmaceutical Co., Ltd.; and Advanced Medical Care Inc.; executive compensation from Cancer Intelligence Care Systems; Inc.; honorarium from Mitsubishi Chemical Holdings Corporation, Mitsubishi Corporation, and Pharma Business Academy; and holds stock in Real World Data Co., Ltd.

\section{Funding}

This work was supported by a Grant-in-Aid for Scientific Research from the Japan Society for the Promotion of Science (grant number: 20H03941).

\section{Authors Contributions}


H.H. conducted the analysis and wrote the first draft of the manuscript. M.T. redrafted the manuscript and commented on the analysis. K.K. advised on the study design and the analysis.

\section{Acknowledgments}

None.

\section{References}

1. McCullough PA, Wolyn R, Rocher LL, Levin RN, O’Neill WW. Acute renal failure after coronary intervention: Incidence, risk factors, and relationship to mortality. Am J Med. 1997;103(5):368-75. https://doi.org/10.1016/S0002-9343(97)00150-2

2. Thakar C V., Christianson A, Freyberg R, Almenoff P, Render ML. Incidence and outcomes of acute kidney injury in intensive care units: A Veterans Administration study. Crit Care Med. 2009;37(9):2552-8. https://doi.org/10.1097/CCM.0b013e3181a5906f

3. Jabara R, Gadesam RR, Pendyala LK, Knopf WD, Chronos N, Chen JP, et al. Impact of the Definition Utilized on the Rate of Contrast-Induced Nephropathy in Percutaneous Coronary Intervention. Am J Cardiol. 2009;103(12):1657-62. https://doi.org/10.1016/j.amjcard.2009.02.039

4. James MT, Samuel SM, Manning MA, Tonelli M, Ghali WA, Faris P, et al. Contrast-induced acute kidney injury and risk of adverse clinical outcomes after coronary angiography: A systematic review and meta-analysis. Circulation: Cardiovascular Interventions. 2013;6:37-43. https://doi.org/10.1161/CIRCINTERVENTIONS.112.974493

5. Suh SH, Kim CS, Choi JS, Bae EH, Ma SK, Kim SW. Acute kidney injury in patients with sepsis and septic shock: Risk factors and clinical outcomes. Yonsei Med J. 2013;54(4):965-72. https://doi.org/10.3349/ymj.2013.54.4.965

6. Plataki M, Kashani K, Cabello-Garza J, Maldonado F, Kashyap R, Kor DJ, et al. Predictors of Acute kidney injury in septic shock patients: An observational cohort study. Clinical Journal of the American Society of Nephrology. 2011;6:1744-51. https://doi.org/10.2215/CJN.05480610

7. Bainey KR, Rahim S, Etherington K, Rokoss ML, Natarajan MK, Velianou JL, et al. Effects of withdrawing vs continuing renin-angiotensin blockers on incidence of acute kidney injury in patients with renal insufficiency undergoing cardiac catheterization: Results from the Angiotensin Converting Enzyme Inhibitor/Angiotensin Receptor Bloc. Am Heart J. 2015;170(1):110-6. https://doi.org/10.1016/j.ahj.2015.04.019

8. Wolak T, Aliev E, Rogachev B, Baumfeld Y, Cafri C, Abu-Shakra M, et al. Renal safety and angiotensin II blockade medications in patients undergoing non-emergent coronary angiography: A randomized controlled study. Isr Med Assoc J. 2013;15(11):682-7.

9. Penny W, Andrew M, Tomlinson LA, Caskey F, Blakeman T, Tomson C, et al. What are the risks and benefits of temporarily discontinuing medications to prevent acute kidney injury? A systematic 
review and meta-analysis Penny. BMJ Open. 2017;7:e012674. https://doi.org/10.1136/bmjopen2016

10. Rosenstock JL, Bruno R, Kim JK, Lubarsky L, Schaller R, Panagopoulos G, et al. The effect of withdrawal of ACE inhibitors or angiotensin receptor blockers prior to coronary angiography on the incidence of contrast-induced nephropathy. Int Urol Nephrol. 2008;40(3):749-55. https://doi.org/10.1007/s11255-008-9368-1

11. Sanders G, Coeytaux R, Dolor R, Hasselblad V, Patel U, Powers B, et al. Angiotensin-Converting Enzyme Inhibitors (ACEls), Angiotensin II Receptor Antagonists (ARBs), and Direct Renin Inhibitors for Treating Essential Hypertension: An Update. Angiotensin-Converting Enzym Inhib (ACEls), Angiotensin II Recept Antagon (ARBs), Direct Renin Inhib Treat Essent Hypertens An Updat. 2011; (34):368.

12. Takeuchi M, Ogura M, Minoura T, Inagaki N, Kawakami K. Comparative Effectiveness of SodiumGlucose Cotransporter-2 Inhibitors Versus Other Classes of Glucose-Lowering Medications on Renal Outcome in Type 2 Diabetes. Mayo Clin Proc. 2020;95:265-73. https://doi.org/10.1016/j.mayocp.2019.12.004

13. Ide K, Fujiwara T, Shimada N, Tokumasu H. Influence of acetaminophen on renal function: a longitudinal descriptive study using a real-world database. Int Urol Nephrol. 2021;53(1):129-35. https://doi.org/10.1007/s11255-020-02596-7

14. Williams LMS, Walker GR, Loewenherz JW, Gidel LT. Association of Contrast and Acute Kidney Injury in the Critically III: A Propensity-Matched Study. Chest. 2020;157(4):866-76. https://doi.org/10.1016/j.chest.2019.10.005

15. R M, AP de F, AM R, A C, H M. Defined daily dose (DDD) and its potential use in clinical trials of resistant hypertension. Int J Cardiol. 2016;202:515-6. https://doi.org/10.1016/J.IJCARD.2015.09.096

16. Teng L, Xin H, Blix H, Tsutani K. Review of the use of defined daily dose concept in drug utilisation research in China. Pharmacoepidemiol Drug Saf. 2012;21(10):1118-24. https://doi.org/10.1002/PDS.3240

17. Austin PC. An Introduction to Propensity Score Methods for Reducing the Effects of Confounding in Observational Studies. Multivariate Behav Res. 2011;46:399-424. https://doi.org/10.1080/00273171.2011.568786

18. Austin PC. A critical appraisal of propensity-score matching in the medical literature between 1996 and 2003. Stat Med. 2008;27(12):2037-49. https://doi.org/10.1002/sim.3150

19. Austin PC. Balance diagnostics for comparing the distribution of baseline covariates between treatment groups in propensity-score matched samples. Stat Med. 2009;28(25):3083-107. https://doi.org/10.1002/sim.3697

20. Rhee C, Dantes R, Epstein L, Murphy DJ, Seymour CW, Iwashyna TJ, et al. Incidence and trends of sepsis in US hospitals using clinical vs claims data, 2009-2014. JAMA - J Am Med Assoc. 2017;318(13):1241-9. https://doi.org/10.1001/jama.2017.13836 
21. Khwaja A. KDIGO clinical practice guidelines for acute kidney injury. Vol. 120, Nephron - Clinical Practice. 2012;120:c179-84. https://doi.org/10.1159/000339789

22. Normand SLT, Landrum MB, Guadagnoli E, Ayanian JZ, Ryan TJ, Cleary PD, et al. Validating recommendations for coronary angiography following acute myocardial infarction in the elderly: $\mathrm{A}$ matched analysis using propensity scores. J Clin Epidemiol. 2001;54(4):387-98. https://doi.org/10.1016/S0895-4356(00)00321-8

23. Frohlich ED. Angiotensin convertin enzyme inhibitors. Present and future. Hypertension. 1989;13(5 SUPPL. I):125-30. https://doi.org/10.1161/01.hyp.13.5_suppl.i125

24. Li B, Yao J, Kawamura K, Oyanagi-Tanaka Y, Hoshiyama M, Morioka T, et al. Real-time observation of glomerular hemodynamic changes in diabetic rats: Effects of insulin and ARB. Kidney Int. 2004;66(5):1939-48. https://doi.org/10.1111/j.1523-1755.2004.00979.x

25. Deray G, Martinez F, Cacoub P, Baumelou B, Baumelou A, Jacobs C. A role for adenosine calcium and ischemia in radiocontrast-induced intrarenal vasoconstriction. Am J Nephrol. 1990;10(4):316-22. https://doi.org/10.1159/000168126

26. Weisberg LS, Kurnik PB, Kurnik BRC. Radiocontrast-induced nephropathy in humans: Role of renal vasoconstriction. Kidney Int. 1992;41(5):1408-15. https://doi.org/10.1038/ki.1992.206

27. Idée JM, Lancelot E, Pines E, Corot C. Prophylaxis of lodinated Contrast Media-Induced Nephropathy: A Pharmacological Point of View. Invest Radiol. 2004;39(3):155-70. https://doi.org/10.1097/01.rli.0000101483.60710.2c

28. Trivedi HS, Moore H, Nasr S, Aggarwal K, Agrawal A, Goel P, et al. A randomized prospective trial to assess the role of saline hydration on the development of contrast nephrotoxicity. Nephron Clin Pract. 2003;93(1):29-34. https://doi.org/10.1159/000066641

29. Mueller C, Buerkle G, Buettner HJ, Petersen J, Perruchoud A, Eriksson U, et al. Prevention of contrast media-associated nephropathy: randomized comparison of 2 hydration regimens in 1620 patients undergoing coronary angioplasty. Arch Intern Med. 2002;162(3):329-36. https://doi.org/10.1001/ARCHINTE.162.3.329

30. Day AG. Why the Propensity for Propensity Scores? Crit Care Med. 2015;43(9):2024-6. https://doi.org/10.1097/CCM.0000000000001175

31. Kitsios GD, Dahabreh IJ, Callahan S, Paulus JK, Campagna AC, Dargin JM. Can We Trust Observational Studies Using Propensity Scores in the Critical Care Literature? A Systematic Comparison with Randomized Clinical Trials. Crit Care Med. 2015;43(9):1870-9. https://doi.org/10.1097/CCM.0000000000001135

32. Stuart EA. Developing practical recommendations for the use of propensity scores: Discussion of "A critical appraisal of propensity score matching in the medical literature between 1996 and 2003" by Peter Austin, Statistics in Medicine. Statistics in Medicine. 2008;27:2062-5. https://doi.org/10.1002/sim.3207

33. McDonald JS, McDonald RJ, Williamson EE, Kallmes DF, Kashani K. Post-contrast acute kidney injury in intensive care unit patients: a propensity score-adjusted study. Intensive Care Med. 2017;1-11. 
https://doi.org/10.1007/s00134-017-4699-y

34. Jurado-Román A, Hernández-Hernández F, García-Tejada J, Granda-Nistal C, Molina J, Velázquez M, et al. Role of hydration in contrast-induced nephropathy in patients who underwent primary percutaneous coronary intervention. Am J Cardiol. 2015;115(9):1174-8.

https://doi.org/10.1016/j.amjcard.2015.02.004

35. Putzu A, Boscolo Berto M, Belletti A, Pasotti E, Cassina T, Moccetti T, et al. Prevention of ContrastInduced Acute Kidney Injury by Furosemide With Matched Hydration in Patients Undergoing Interventional Procedures: A Systematic Review and Meta-Analysis of Randomized Trials. JACC Cardiovasc Interv. 2017;10(4):355-63. https://doi.org/10.1016/j.jcin.2016.11.006

36. Wheeler DC, Stefansson B V, Batiushin M, Bilchenko O, Cherney DZI, Chertow GM, et al. The dapagliflozin and prevention of adverse outcomes in chronic kidney disease (DAPA-CKD) trial: Baseline characteristics. Nephrol Dial Transplant. 2020;35(10):1700-11. https://doi.org/10.1093/ndt/gfaa234

\section{Tables}

Table 1. Baseline characteristics of each group in the entire cohort and PS-matched cohort 
Entire cohort

Cases in

Reduction

Group

$(n=896)$

$599(66.9)$

$74.6(9.0)$

$5.4(3.5)$

$44.9(10.7)$

eGFR (mean (SD))

Diuretics (\%)

NSAID (\%)

Heart failure

Platinum (\%)

Aminoglycoside (\%)

Glycopeptide (\%)

NAC (\%)

Sodium bicarbonate (\%) $\quad 0(0.0)$

Hydration (\%)

Infection (\%)

Operation (\%)

Transfusion (\%)

ICU admission (\%)

Admission year

$-2012(\%)$

2013-2016 (\%)

2017-2019 (\%)

$69(7.7)$

$4(0.4)$

$28(3.1)$

$49(5.5)$

$38(4.2)$

$99(11.0)$

Cases in SDif Cases in Cases in SDif

Control

Group

$(n=2393)$

Reduction Control

Group Group

$(\mathrm{n}=896) \quad(\mathrm{n}=$

1744)

1606
$(67.1)$

$0.01599(66.9)$

1180

(67.7)

0.02

$74.6(9.0) \quad 0.00$

$5.4(3.5) \quad 0.01$

$5.3(3.5) \quad 0.03 \quad 5.4(3.5)$

$0.02 \quad 44.9(10.7)$

44.9

(10.5)

(10.6)

494 (55.1) $\quad \begin{array}{ll}1128 \\ \end{array} \quad(47.1)$

$0.16 \quad 494(55.1)$

942

(54.0)

$111(6.4) \quad 0.05$

$127(5.3)$

$0.10 \quad 69(7.7)$

45 (2.6) $\quad 0.01$

$81(3.4) \quad 0.04 \quad 24(2.7)$

$0.03 \quad 0(0.0)$

$0(0.0)$

$1(0.0)$

$0.03 \quad 0(0.0)$

$0(0.0)$

$1(0.0)$

$0.05 \quad 2(0.2)$

$0(0.0)$

0.07

$1(0.0)$

$0(0.0)$

$0(0.0)$

$0(0.0)$

$0.12 \quad 0(0.0)$

$0(0.0)$

$17(0.7)$

$0.18 \quad 366(40.8)$

725

(41.6)

0.01

(49.9)

$5(0.2)$

$0.04 \quad 4(0.4)$

$5(0.3)$

0.03

$84(3.5)$

$0.02 \quad 28(3.1)$

$46(2.6)$

0.03

$126(5.3)$

$0.01 \quad 49(5.5)$

$85(4.9)$

0.03

$119(5.0)$

$0.04 \quad 38(4.2)$

$73(4.2)$

0.00

$259(10.8) \quad 0.01 \quad 99(11.0)$

183

(10.5)

$390(43.5) \quad 1262$

$-0.18 \quad 390(43.5)$

805

(46.2)

$407(45.4) \quad 872(36.4) \quad 0.18 \quad 407(45.4)$

756

(43.3)
0.02 $-0.05$ 
Primary diagnosis

\begin{tabular}{|c|c|c|c|c|c|c|}
\hline Cardiovascular (\%) & $731(81.6)$ & $\begin{array}{c}1903 \\
(79.5)\end{array}$ & 0.05 & $731(81.6)$ & $\begin{array}{l}1441 \\
(82.6)\end{array}$ & -0.03 \\
\hline Other (\%) & $31(3.5)$ & $89(3.7)$ & -0.01 & $41(4.6)$ & $78(4.5)$ & 0.02 \\
\hline Metabolic (\%) & $30(3.3)$ & $103(4.3)$ & -0.05 & $31(3.5)$ & $54(3.1)$ & 0.01 \\
\hline Cerebrovascular (\%) & $16(1.8)$ & $53(2.2)$ & -0.03 & $30(3.3)$ & $54(3.1)$ & 0.01 \\
\hline Digestive (\%) & $15(1.7)$ & $39(1.6)$ & 0.01 & $16(1.8)$ & $29(1.7)$ & 0.01 \\
\hline $\begin{array}{l}\text { Septicemia/other } \\
\text { infections (\%) }\end{array}$ & $15(1.7)$ & $35(1.5)$ & 0.02 & $15(1.7)$ & $28(1.6)$ & 0.01 \\
\hline Injury/Poisoning (\%) & $10(1.1)$ & $18(0.8)$ & 0.03 & $15(1.7)$ & $28(1.6)$ & 0.00 \\
\hline Neoplasm (\%) & $3(0.3)$ & $12(0.5)$ & -0.03 & $10(1.1)$ & $17(1.0)$ & 0.00 \\
\hline Peripheral vascular (\%) & $3(0.3)$ & $7(0.3)$ & 0.00 & $3(0.3)$ & $7(0.4)$ & -0.02 \\
\hline Respiratory (airway) (\%) & $1(0.1)$ & $2(0.1)$ & 0.00 & $3(0.3)$ & $6(0.3)$ & 0.00 \\
\hline $\begin{array}{l}\text { Respiratory } \\
\text { (parenchymal) (\%) }\end{array}$ & $41(4.6)$ & $132(5.5)$ & -0.04 & $1(0.1)$ & $2(0.1)$ & 0.01 \\
\hline
\end{tabular}

$\mathrm{CCl}$, Charlson comorbidity index; ICU, intensive care unit; NAC, N-acetyl cysteine; NSAID, nonsteroidal antiinflammatory drug; PS, propensity score; SD, standard deviation; SDif, standardized difference.

Table 2. Odds ratios for AKI, in-hospital dialysis and in-hospital death in the entire cohort and in the PSmatched cohort

\begin{tabular}{|c|c|c|c|c|c|c|}
\hline & \multicolumn{3}{|l|}{ Entire cohort } & \multicolumn{3}{|c|}{ PS-matched cohort } \\
\hline & $\begin{array}{l}\text { Events in } \\
\text { Reduction group }\end{array}$ & $\begin{array}{l}\text { Events in } \\
\text { Control group }\end{array}$ & $\begin{array}{l}\text { Odds Ratio } \\
(95 \% \mathrm{Cl})\end{array}$ & $\begin{array}{l}\mathrm{P} \\
\text { Value }\end{array}$ & $\begin{array}{l}\text { Odds Ratio } \\
(95 \% \mathrm{Cl})\end{array}$ & $\begin{array}{l}\mathrm{P} \\
\text { Value }\end{array}$ \\
\hline AKI & $42(4.7)$ & $121(5.1)$ & $\begin{array}{l}0.92(0.64- \\
1.32)\end{array}$ & 0.66 & $\begin{array}{l}1.00(0.69- \\
1.47)\end{array}$ & 0.98 \\
\hline $\begin{array}{l}\text { Dialysis in } \\
\text { hospital }\end{array}$ & $16(1.8)$ & $24(1.0)$ & $\begin{array}{l}1.79(0.95- \\
3.39)\end{array}$ & 0.07 & $\begin{array}{l}1.98(0.98- \\
3.97)\end{array}$ & 0.06 \\
\hline $\begin{array}{l}\text { Death in } \\
\text { hospital }\end{array}$ & $13(1.5)$ & 31 (1.3) & $\begin{array}{l}1.12(0.58- \\
2.15)\end{array}$ & 0.73 & $\begin{array}{l}1.28(0.63- \\
2.58)\end{array}$ & 0.49 \\
\hline
\end{tabular}

$\mathrm{AKI}$, acute kidney injury; $\mathrm{Cl}$, confidence interval; PS, propensity score.

Table 3. Sensitivity analysis changing the length of the period of dose reduction in the PS-matched cohort 


\begin{tabular}{lll} 
& Odds Ratio $(95 \% \mathrm{Cl})$ & $\mathrm{P}$ Value \\
\hline 1 day & $1.07(0.69-1.65)$ & 0.76 \\
\hline 3 days & $1.00(0.69-1.47)$ & 0.98 \\
\hline 7 days & $1.07(0.77-1.50)$ & 0.68 \\
\hline 14 days & $0.99(0.71-1.39)$ & 0.96
\end{tabular}

Table 4. Subgroup analysis investigating interactions with age, type of RAASi, baseline eGFR and degree of reduction.

$$
\text { Odds Ratio }(95 \% \mathrm{Cl}) \quad \text { P Value }
$$

\begin{tabular}{lll} 
Age & & \\
\hline Age $>65$ & $1.14(0.71-1.83)$ & 0.59 \\
\hline Age $\leq 65$ & $0.59(0.23-1.51)$ & 0.27 \\
\hline Type of RAASi & & \\
\hline ACEi & $0.69(0.30-1.57)$ & 0.37 \\
\hline ARB & $1.31(0.80-2.16)$ & 0.29 \\
\hline Aldosterone Blocker & $1.00(0.00-$ Inf $)$ & 1.00 \\
\hline DRI & Not enough cases to calculate & Not applicable
\end{tabular}

Diabetes

\begin{tabular}{ccc} 
Yes & $0.90(0.30-2.64)$ & 0.84 \\
\hline No & $1.05(0.66-1.68)$ & 0.83
\end{tabular}

Baseline eGFR

$\begin{array}{lll}\text { eGFR }>45 & 0.78(0.30-2.03) & 0.61 \\ 30<\text { eGFR } \leq 45 & 1.31(0.72-2.40) & 0.37 \\ \text { eGFR } \leq 30 & 0.88(0.34-2.26) & 0.79\end{array}$

Degree of reduction

Discontinuation

$1.48(0.76-2.89)$

0.25

$\begin{array}{lll}\text { Reduction (excluding discontinuation) } & 0.86(0.49-1.51) & 0.60\end{array}$

$\mathrm{ACEi}$, angiotensin-converting enzyme inhibitor; $\mathrm{ARB}$, angiotensin receptor blocker; $\mathrm{Cl}$, confidence interval; $\mathrm{DRI}$, direct renin inhibitor; eGFR, estimated glomerular filtration rate; RAASis, renin-angiotensinaldosterone system inhibitors 


\section{Figures}

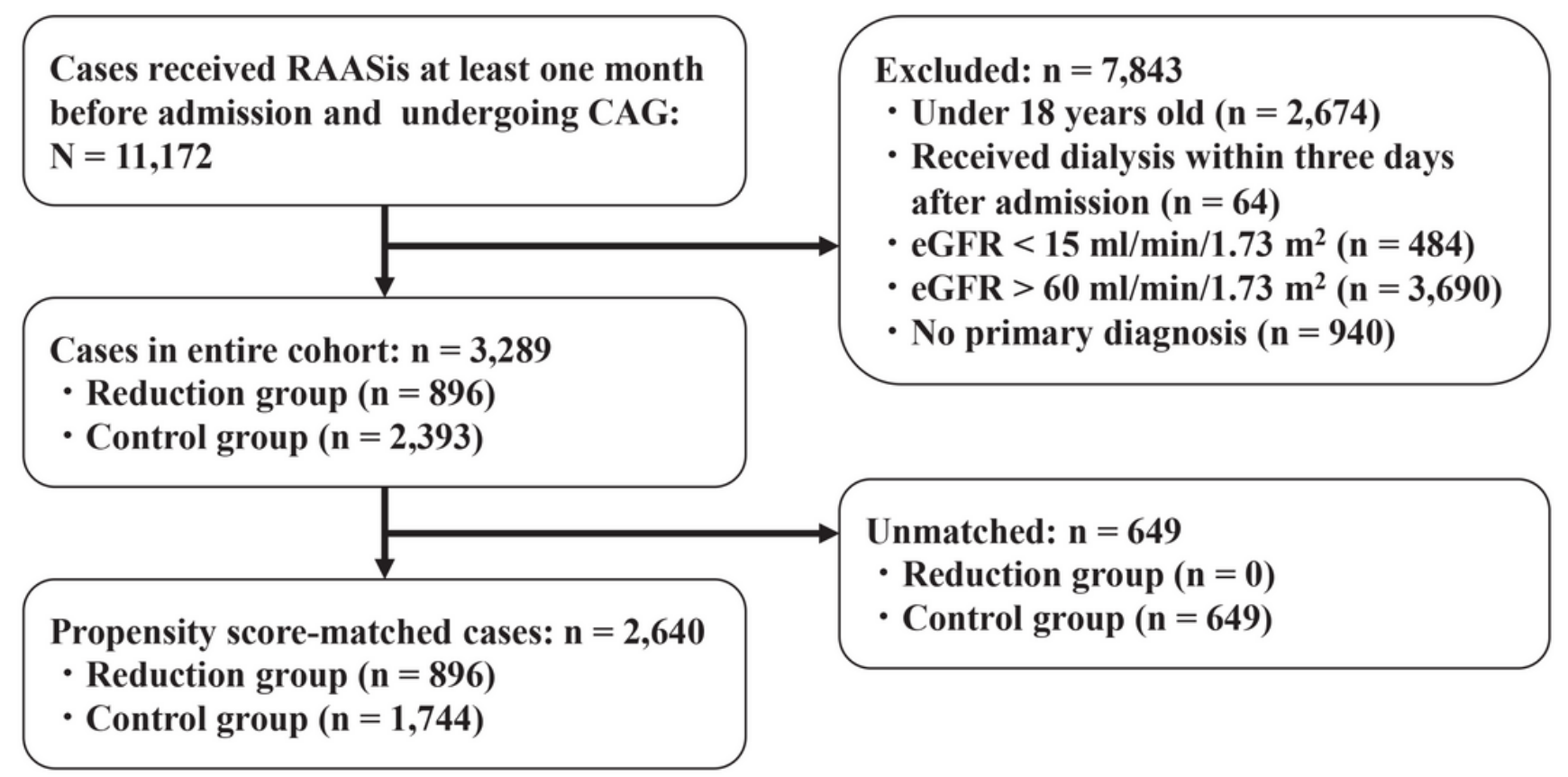

Figure 1

Flow diagram of case selection and matching. CAG, coronary artery angiography; eGFR, estimated glomerular filtration rate; RAASis, renin-angiotensin-aldosterone system inhibitors.

\section{Supplementary Files}

This is a list of supplementary files associated with this preprint. Click to download.

- SupplementaryTable.docx 